\title{
Experimental Investigation of the Mass Transfer Coefficients of Metals in Stainless Steel Crude Alloy from Mixed Low-grade Chromite and Nickel Laterite Ores
}

\author{
Romie D. Laranjo ${ }^{1, *}$ and Vannie Joy T. Resabal ${ }^{2}$ \\ ${ }^{1}$ College of Engineering, Jose Rizal Memorial State University, Dapitan City 7101, Philippines \\ ${ }^{2}$ Metallurgical, Ceramics and Mining Engineering Department, College of Engineering, MSU-Iligan Institute of Technology, Iligan \\ City 9200, Philippines
}

Received 27 July 2019; Accepted 11 February 2020

\begin{abstract}
The processing of liquid steel uses a very high temperature. The reaction between the liquid steel and the slag generates liquid-liquid mass transfer of the species involved. The mass transfer coefficients of the metals present in the stainless steel crude alloy were the central point of this study. The study in particular aimed to estimate the liquid-liquid mass transport coefficients of the species involved in this very important process. These were evaluated using the experimental results obtained from direct smelting of mixed low-grade chromite and nickel laterite ores. In this investigation, the kinetics of slag-metal reactions was stimulated by metal phase control mechanism and slag phase control mechanism. Results obtained from the experiments showed that the metal phase control was the dominating mechanism in the study as seen from the degree of fit of the experimental data to such mechanism.
\end{abstract}

Keywords: Mass transfer coefficient; Stainless steel crude alloy; Nickel laterite ore; Chromite ore

\section{Introduction}

Pyrometallurgical smelting processes occur at very high temperatures and chemical reactions usually occur very fast at these temperatures, so chemical reactions are usually not rate-controlling. Generally transport control (heat or mass transfer) can be assumed. Liquid-liquid reactions such as slagmetal reactions, mass transport at the interface is a possible rate-controlling step particularly in high-temperature steelmaking [1].

The refining of liquid metal in the metallurgical processes is attained by means of mass transfer reaction that takes place at the interface between the liquid metal and a covering liquid or slag [2]. The mass transfer at the interface between hot metal and slag is very important to control the time of reaction in order to achieve the composition desired by the steelmakers [3]. The productivity of steelmaking processes, including production and refining of liquid steel, depends on the mass transfer rates [4]. Mass transfer possesses a vital role in determining the rate of steelmaking processes. Thus, the evaluation of the mass transfer coefficients of the species involved in the process and the identification of the factors that affect the mass transfer rates are of great importance.

There are many models and techniques that have been developed and adopted to evaluate the mass transfer coefficient. The variations of these techniques and models are dependent on the system being analyzed and the phases involved. Experimentally, high temperature systems are very difficult to investigate so that cold model set-ups analogous to the real converter were employed for the detailed studies of the factors involved in transport controlled reactions. Horiuchi et al. [5] evaluated liquid/liquid mass transfer between different phases with mechanical stirring and they compared it to gas stirring practice. They conducted cold model experiments using liquid paraffin as dispersed phase and ion-exchanged water as continuous phase in a mechanical stirred vessel. In the study of Martin et al. [6], steel phase-slag phase mass transfer coefficients were determined in a cold model similar to a steel converter. The effect of the gas flow rate was studied in bottom and top-bottom combined blowing, comparing the efficiency of each blowing type. In the case of a high-temperature reaction between $2.35 \mathrm{~g}$ Fe-5 wt pet $\mathrm{Al}$ alloy metal droplets with $\mathrm{CaO}-\mathrm{SiO}_{2}-\mathrm{Al}_{2} \mathrm{O}_{3}$ slag at $1650^{\circ} \mathrm{C}$, it was found that the kinetics follow a first-order relationship with respect to aluminum in the metal, and it was concluded that they were controlled by mass transport in the metal phase [7].

In the work of Diao et al. [8], the mass transfer of phosphorus in high-phosphorus hot-metal refining was investigated using $\mathrm{CaO}-\mathrm{Fe}_{t} \mathrm{O}-\mathrm{SiO}_{2}$ slags at $1623 \mathrm{~K}$. Based on a two-film theory kinetic model and experimental results, it was found that the overall mass transfer coefficient, which included the effects of mass transfer in both the slag phase and metal phase, was in the range of 0.0047 to $0.0240 \mathrm{~cm} / \mathrm{s}$. Xie and Oeters [9] set up an investigation of the kinetics of mass transfer of $\mathrm{Mn}$ and $\mathrm{Si}$ between liquid iron and slag in laboratory experiments at $1600^{\circ} \mathrm{C}$ in $\mathrm{MgO}$ crucibles with $1500 \mathrm{~g}$ iron and $250 \mathrm{slag}$. However, neither study discussed the mass transfer coefficients of the species present in the stainless steel crude alloy produced from direct smelting of mixed chromite and nickel laterite ores.

The present study aimed to provide further experimental knowledge for the calculations of liquid-liquid mass transfer coefficients of the metals present in stainless steel crude alloy from direct smelting of mixed low-grade chromite and nickel laterite ores. 


\section{Methodology}

\subsection{Experimental materials and procedure}

Prior to the smelting experiments, the chromite ore from Siayan, Zamboanga del Norte and nickel laterite ore from Surigao district were calcined using a muffle furnace to remove the excess water, carbonates and some volatile matters. All the test materials passed through a $74 \mu \mathrm{m}$ screen using USA standard testing sieve (ASTM E-11). The experimental procedure of the present work was taken from the previous work by the authors [10]. For the convenience of the readers the experimental procedure is briefly summarized as follows: A sample of mixed chromite and nickel laterite ores with a total mass of $20 \mathrm{~g}$ together with a few percent of coal was mixed together and blended until the mixture became homogeneous. The homogenized mixture were placed in a $25 \mathrm{~mm}$ graphite crucible and compacted with a pressure of $20 \mathrm{~kg} / \mathrm{cm}^{2}$ using the fabricated die and punch assembly before charging to the elevator furnace. The smelting time of the study was varied at $30 \mathrm{~min}, 60 \mathrm{~min}, 120$ min and $180 \mathrm{~min}$, respectively and the smelting temperature was held constant at $1600^{\circ} \mathrm{C}$ in an argon atmosphere at a flow rate of $200 \mathrm{~mL} / \mathrm{min}$. The equipment used in the smelting experiments was a laboratory elevator furnace equipped with 8 U-shaped high-quality $\mathrm{MoSi}_{2}$ heating elements. The chemical compositions of the ores were analyzed using an Xray fluorescence spectrometer (XRF). The chemical analysis was carried out using the PANanalytical Axios X-ray fluorescence spectrometer model PW4400. Quantitative analyses of the final samples of the stainless steel crude alloy and slag phases were also performed using gravimetric method, titration method and atomic absorption spectrometry (Shimadzu Atomic Absorption Spectrophotometer model AA-6300), respectively. The chemical compositions of the feed materials are shown in Tab. 1.

Table 1. Chemical composition of the ores, wt.\%

\begin{tabular}{l|l|l|l|l|l|l|l|l|l|l|l|l}
\hline Components & $\mathbf{C r}_{2} \mathbf{O}_{3}$ & $\mathbf{M g O}$ & $\mathbf{F e}_{2} \mathbf{O}_{3}$ & $\mathbf{A l}_{2} \mathbf{O}_{3}$ & $\mathbf{S i O}_{2}$ & $\mathbf{M n O}$ & $\mathbf{N a}_{2} \mathbf{O}$ & $\mathbf{N i O}$ & $\mathbf{P}_{2} \mathbf{O}_{5}$ & $\mathbf{T i O}_{2}$ & $\mathbf{S O}_{3}$ & $\mathbf{L O I}$ \\
\hline Chromite & 40.59 & 13.12 & 21.71 & 15.95 & 4.51 & 0.24 & 0.17 & 0.41 & 0.04 & 0.18 & 0.42 & 0.30 \\
Laterite & 0.54 & 19.78 & 30.88 & 1.12 & 26.75 & 0.33 & - & 2.23 & 0.03 & - & 0.31 & 13.37 \\
\hline
\end{tabular}

LOI is the loss on ignition

In this investigation, the kinetics of slag-metal reactions was determined using the mechanisms described by Richardson [11]. The five cases of possible rate-controlling mechanisms in the slag-metal reaction are illustrated in Fig. 1. The interfacial and bulk concentration are indicated by superscripts $\mathrm{i}$ and $\mathrm{b}$, respectively. However, only Case 1 (Metal phase control) and Case 2 (Slag phase control) are considered in this study.

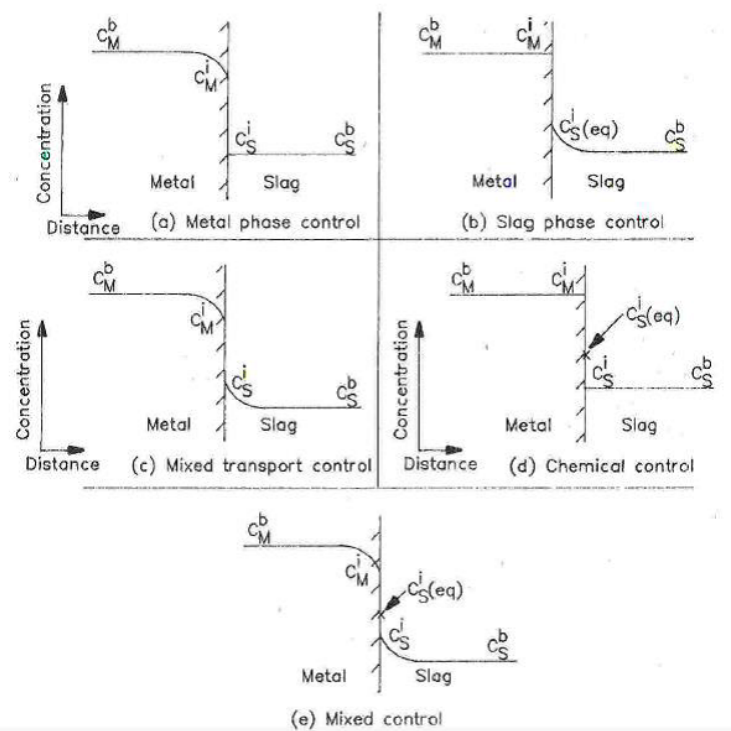

Fig. 1. Five possible rate-controlling mechanisms in slag-metal reaction: metal phase control (a); slag phase control (b); mixed mass transport control (c); chemical control (d) and mixed control (e) [11].

\subsection{Theoretical analysis}

Mass transfer in a fluid can occur by several mechanisms. One of these mechanisms is the molecular or atomic diffusion. Molecular or atomic diffusion in a solid, liquid or gas occurs as a result of the presence of a concentration gradient. The mass transfer coefficients can be calculated with the equations derived by Deo and Boom [12]. According to Fick's first law, the diffusive flux $J_{D_{m}}$ (number of moles per unit time per unit area) is proportional to the concentration gradient, $\frac{\partial c}{\partial x}$ :

$$
J_{D_{m}}=-D_{m}\left(\frac{\partial c}{\partial x}\right)
$$

where $D_{m}$ is the atomic (or molecular) diffusion coefficient. When a steady state is reached, the thickness of the concentration boundary layer $\delta$ and the velocity boundary layer $\quad \delta$ 'become constant. Thus, letting $\delta=\partial x$ and $\partial C=\left(C_{m}^{b}-C_{m}^{i}\right)$, Eq. 1 becomes

$J_{D_{m}}=k_{m}^{D}\left(C_{m}^{b}-C_{m}^{i}\right)$

where $C_{m}^{i}$ and $C_{m}^{b}$ are the interfacial and bulk concentrations, respectively, and

$k_{m}^{D}=\frac{D_{m}}{\delta}$

where $k_{m}^{D}$ is called the diffusion mass transfer coefficient in the metal phase.

Thus the total molar flux $J_{D}$ at the interface of immiscible liquids (in the absence of turbulent diffusion) can be evaluated by

$$
J_{D}=J_{D_{m}}=k_{m}^{D}\left(C_{m}^{b}-C_{m}^{i}\right)
$$

At the interface, the momentum flux approaches to zero, and $k_{m}^{D}$ would be equal to the overall mass transfer coefficient $\left(\mathrm{k}_{\mathrm{m}}\right)$ and the turbulent mass transfer coefficient 
would be eliminated when the fractional contribution of diffusion mass transfer is equal to one. Moreover, the chemical reactions in this study are extremely fast since high temperature is used during the experiments. Thus, a pseudo or instantaneous thermodynamic equilibrium may be assumed to exist at the interface during the small time interval $(\Delta t \rightarrow 0)$, such that (with reference to Figure 1a):

$$
\frac{C_{m}^{e q}}{C_{s}^{e q}}=\frac{C_{m}^{i}}{C_{s}^{i}}=L_{p}
$$

where $L_{p}$ is the equilibrium constant, sometimes denoted as the partition or distribution coefficient; $C_{m}^{e q}$ and $C_{s}^{e q}$ are the ultimate thermodynamic equilibrium concentrations in metal and slag, respectively.

Substituting Eq. 5 into Eq. 4 and from Fig. 1a for metal phase control, $C_{s}^{i}=C_{s}^{b}$ and hence the mass transfer coefficient can be expressed by

$$
J_{m}=-\frac{d C}{d t} \frac{V_{m}}{A}=k_{m}\left(C_{m}^{b}-L_{p} C_{s}^{i}\right)
$$

where $V_{m}$ is the volume of the metal $\left(\mathrm{m}^{3}\right)$ and $A$ is the nominal area of the interface $\left(\mathrm{m}^{2}\right)$. Since gas stirring is not employed in the present study, the cross section area of the crucible is considered as the slag/metal interfacial area. The graphite crucible used in the experiment has the following data: $\mathrm{h}=55 \mathrm{~mm}, \mathrm{ID}=25 \mathrm{~mm}$ and $\mathrm{OD}=32 \mathrm{~mm}$. Thus the value of the interfacial area is $490.9 \mathrm{~mm}^{2}$.

If the slag does not contain any amount of metal to start with, then from mass balance the molar concentrations $C_{s}^{b}, C_{m}^{b}, C_{s}^{e q}, C_{m}^{e q}$ appearing in Eqs. 5 and 6 can be evaluated as

$$
\begin{aligned}
& C_{s}^{b}=\frac{W M\left(m_{o}-m_{t}\right)}{W S}\left(\frac{\rho_{s}}{100}\right)\left(\frac{1}{A W_{m}}\right) \\
& C_{m}^{b}=\rho_{m}\left(\frac{m_{t}}{A W_{m}}\right)\left(\frac{1}{100}\right) \\
& C_{m}^{e q}=\rho_{m}\left(\frac{m_{e}}{A W_{m}}\right)\left(\frac{1}{100}\right)
\end{aligned}
$$

$$
\begin{aligned}
& C_{s}^{e q}=\frac{W M\left(m_{o}-m_{e}\right)}{W S}\left(\frac{\rho_{s}}{100}\right)\left(\frac{1}{A W_{m}}\right) \\
& \frac{C_{m}^{e q}}{C_{s}^{e q}}=L_{p}
\end{aligned}
$$

where WM is weight of metal; WS is weight of slag; $A W_{m}$ is atomic weight of metal; $m_{o}$ is wt $\%$ metal at time $0, m_{t}$ is wt $\%$ metal at time $\mathrm{t} ; m_{e}$ is wt $\%$ metal at equilibrium; $\rho_{m}$ is density of metal; $\rho_{s}$ is density of slag.

Substituting Eq. 7 to 11 into Eq. 6 and integrating gives the equations for the mass transfer coefficients in the metal and slag phases. This can be expressed by the following equations:

$$
\begin{aligned}
& -\ln \left(\frac{m_{t}-m_{e}}{m_{o}-m_{e}}\right)=k_{m} A \frac{\rho_{m}}{W M} t\left(\frac{m_{o}}{m_{o}-m_{e}}\right) \\
& -\ln \left(\frac{s_{t}-s_{e}}{s_{o}-s_{e}}\right)=k_{s} A \frac{\rho_{s}}{W S} t\left(\frac{s_{o}}{s_{o}-s_{e}}\right)
\end{aligned}
$$

where $k_{m}$ and $k_{s}$ are mass transfer coefficients in the metal phase and slag phase, respectively. Using the experimental data, the slope of the straight line in the graphical plot of $-\ln \left[\left(m_{t}-m_{e}\right) /\left(m_{o}-m_{e}\right)\right]$ versus time is determined to evaluate the mass transfer coefficient at different time intervals.

\section{Results and Discussion}

\subsection{Metal phase control}

Tab. 2 presents the chemical analysis of the metals present in the crude alloy which was smelted at $1600^{\circ} \mathrm{C}$ and the corresponding weights of the metals at different time intervals. As the time was increased from 30 to $180 \mathrm{~min}$, the weights of the metals clearly increased. The data also reveal that the metal concentration of Fe decreased while the Mn and Si contents increased gradually. The data in Tab. 2 are used for the calculation of the densities of the crude alloy at different time intervals.

Table 2. Chemical analysis of the metals in the crude alloy smelted at $1600^{\circ} \mathrm{C}$

\begin{tabular}{c|c|c|c|c|c|c|c|c}
\hline Time (min) & $\mathbf{F e}$ & $\mathbf{C r}$ & $\mathbf{N i}$ & $\mathbf{M n}$ & $\mathbf{S i}$ & $\mathbf{A l}$ & $\mathbf{M g}$ & $\mathbf{T i}$ \\
\hline 30 & 58.53 & 15.20 & 5.11 & 2.10 & 11.33 & 0.37 & 0.40 & 0.16 \\
60 & 50.56 & 18.30 & 5.84 & 12.04 & 11.39 & 0.25 & 0.42 & 0.28 \\
120 & 53.92 & 16.13 & 4.78 & 7.93 & 14.02 & 0.54 & 1.17 & 0.26 \\
$180(\mathrm{Eq})$ & 54.37 & 16.77 & 4.81 & 7.09 & 14.22 & 0.46 & 0.87 & 0.25 \\
\hline
\end{tabular}

The densities of the metal samples were determined using the data presented in Tab. 2 and the calculated densities are $6371.47 \mathrm{~kg} / \mathrm{m}^{3}, 6042.84 \mathrm{~kg} / \mathrm{m}^{3}$ and $5660.25 \mathrm{~kg} / \mathrm{m}^{3}$ at 30,60 and $120 \mathrm{~min}$, respectively. The interfacial area which is assumed as the cross section area of the crucible has the value of $4.909 \times 10^{-4} \mathrm{~m}^{2}$. The area and density at different time intervals were obtained for the calculation of the order of magnitude of mass transfer coefficients.
Plotting the left hand side of Eq. 12 against the reaction time provided a straight line with the slope for the mass transfer coefficient calculation. Fig. 2 shows the graphical plot of $-\ln \left[\left(m_{t}-m_{e}\right) /\left(m_{o}-m_{e}\right)\right]$ versus time which determined the absolute values of the slope of the line. The slopes of the metals present in the crude alloy were taken at different time intervals to calculate the mass transfer coefficients of $\mathrm{Fe}, \mathrm{Cr}, \mathrm{Ni}, \mathrm{Mn}$ and $\mathrm{Si}$. In the present study, it 
was assumed that the equilibrium metal contents, $m_{e}$, is equal to the metal contents at 180 minutes.

The mass transfer coefficients derived from experimental data for iron, chromium, nickel, manganese and silicon of the crude alloy in this study clearly support the finding that the mass transport of chromium controls the rate at which the reaction proceeds. Chromium is thus the slowest diffusing species. The mass transfer coefficient for chromium which is $1.68 \times 10^{-6} \mathrm{~m} / \mathrm{min}$ is an order of magnitude lower than the mass transfer coefficients of silicon, manganese, iron and nickel in the crude alloy.

(a) $\mathrm{Fe}$

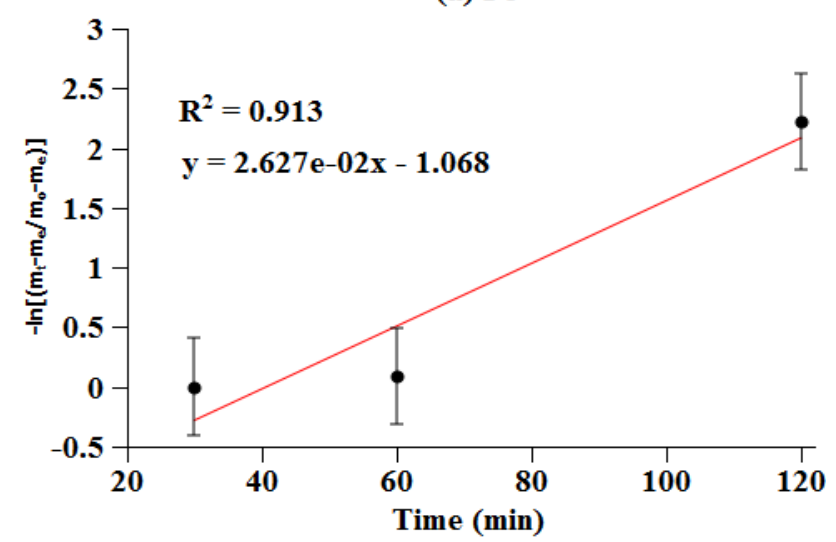

(b) $\mathrm{Cr}$

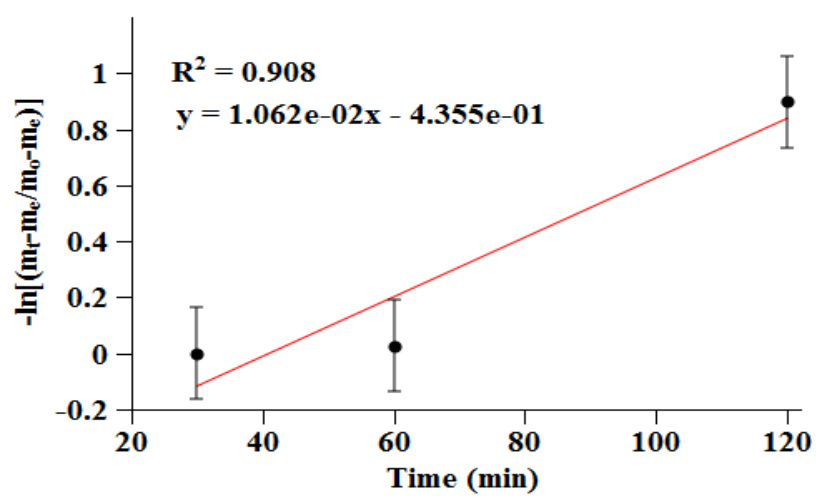

(c) $\mathrm{Ni}$

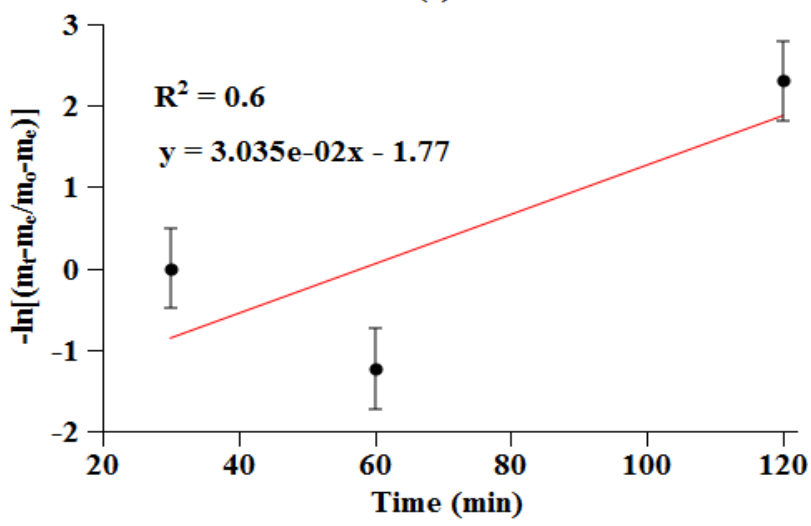

(d) Mn

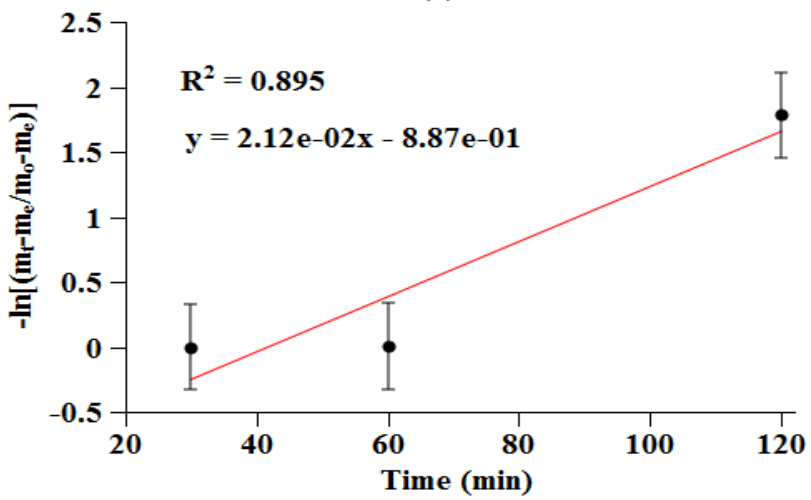

(e) $\mathrm{Si}$

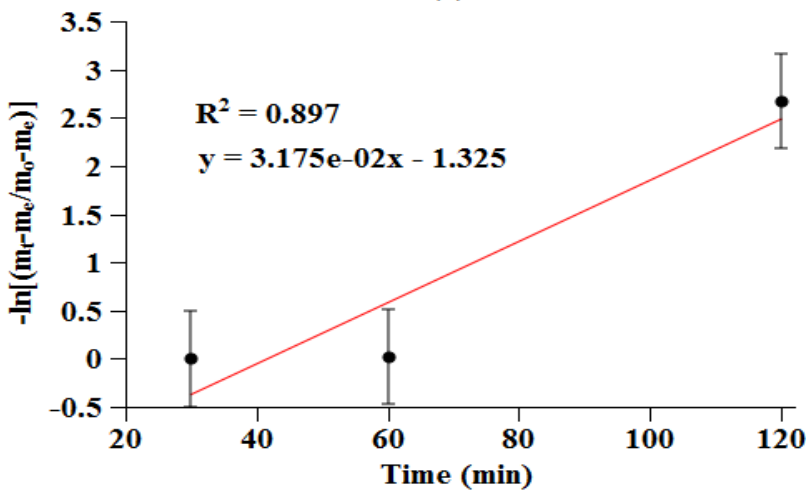

Fig. 2. Graphical plot of $-\ln \left[\left(m_{t}-m_{e}\right) /\left(m_{o}-m_{e}\right)\right]$ versus time for metal phase control. (a) Iron; (b) Chromium;

(c) Nickel; (d) Manganese; (e) Silicon

Tab. 3 shows the summary of the computed slope of the straight line in graphical plot of $-\ln \left[\left(m_{t}-m_{e}\right) /\left(m_{o}-m_{e}\right)\right]$ versus time and the corresponding magnitude of mass transfer coefficients at different time intervals. The mass transfer coefficients were calculated from the slope of the straight line and using Eq. 12. The slowest and fastest rates among the metals present in the crude alloy at $1600^{\circ} \mathrm{C}$ were determined. It is clearly seen from the table that the fastest rate was obtained by $\mathrm{Mn}$ followed by $\mathrm{Si}, \mathrm{Fe}, \mathrm{Ni}$ and $\mathrm{Cr}$ got the slowest rate. It can be deduced that the mass transfer of $\mathrm{Cr}$ in the metal phase is rate controlling.

Table 3. Mass transfer coefficients of the metals at $1600^{\circ} \mathrm{C}$

\begin{tabular}{c|c|c|c|c|c}
\hline Elements & $\mathbf{F e}$ & $\mathbf{C r}$ & $\mathbf{N i}$ & $\mathbf{M n}$ & $\mathbf{S i}$ \\
\hline $\mathbf{k}_{\mathbf{m}}$ & $2.86 \times$ & $1.68 \times$ & $2.73 \times$ & $7.72 \times$ & $1.24 \times$ \\
$(\mathbf{m} / \mathbf{m i n})$ & $10^{-6}$ & $10^{-6}$ & $10^{-6}$ & $10^{-5}$ & $10^{-5}$ \\
\hline
\end{tabular}

\subsection{Slag phase control}

The procedure for deriving the rate equation for slag phase control is exactly the same as described in metal phase control. Tab. 4 presents the chemical analysis of the slags after smelting at $1600^{\circ} \mathrm{C}$ at different time intervals. It can also be seen from the table that the slags still contained higher concentrations of $\mathrm{SiO}_{2}$ and $\mathrm{MgO}$. The reason for this is that these oxides are stable so that they were difficult to be reduced [13].

Table 4. Chemical analysis of the slags after smelting at $1600^{\circ} \mathrm{C}$

\begin{tabular}{c|c|c|c|c|c|c|c|c}
\hline Time (min) & $\mathbf{F e}_{\mathbf{2}} \mathbf{O}_{\mathbf{3}}$ & $\mathbf{C r}_{\mathbf{2}} \mathbf{O}_{\mathbf{3}}$ & $\mathbf{N i O}$ & $\mathbf{M n O}$ & $\mathbf{S i O}_{\mathbf{2}}$ & $\mathbf{A l}_{\mathbf{2}} \mathbf{O}_{\mathbf{3}}$ & $\mathbf{M g O}$ & $\mathbf{T i O}$ \\
\hline 30 & 2.18 & 0.90 & 0.46 & 2.04 & 35.02 & 8.56 & 38.93 & 0.12 \\
60 & 3.58 & 1.91 & 0.49 & 6.73 & 39.78 & 8.14 & 37.46 & 0.27 \\
120 & 2.77 & 0.92 & 0.46 & 2.83 & 34.58 & 8.21 & 40.51 & 0.17 \\
$180(\mathrm{Eq})$ & 2.3 & 0.8 & 0.31 & 2.50 & 37.90 & 9.59 & 44.35 & 0.11 \\
\hline
\end{tabular}


The slopes of the line at different time intervals were also obtained for the calculation of the order of magnitude of mass transfer coefficients for the slag phase control using Eq. 13. The densities of the slag samples were determined using the data presented in Tab. 5 above and the corresponding weights of the slag samples at different time intervals. The calculated densities are $2418.15 \mathrm{~kg} / \mathrm{m}^{3}, 2305.003 \mathrm{~kg} / \mathrm{m}^{3}$ and 2373.03 $\mathrm{kg} / \mathrm{m}^{3}$ at 30,60 and $120 \mathrm{~min}$, respectively. The interfacial area is equal to $4.909 \times 10^{-4} \mathrm{~m}^{2}$.

The value of $k_{s}$ (mass transfer coefficient of oxides) was obtained from the graphical plot of $-\ln \left[\left(s_{t}-s_{e}\right) /\left(s_{o}-s_{e}\right)\right]$ versus time for slag phase control using Eq. 13. The slopes of the oxides present in the slag obtained from the graphical plot were taken at different time intervals to calculate the mass transfer coefficients of $\mathrm{Fe}_{2} \mathrm{O}_{3}, \mathrm{Cr}_{2} \mathrm{O}_{3}, \mathrm{NiO}, \mathrm{MnO}$ and $\mathrm{SiO}_{2}$.

Tab. 5 contains the summary of the result from the computed slope of the straight line in the graphical plot of $-\ln \left[\left(s_{t}-s_{e}\right) /\left(s_{o}-s_{e}\right)\right]$ versus time with the corresponding magnitude of mass transfer coefficients at different time intervals for slag phase control. The mass transfer coefficients were calculated to determine the slowest and fastest rate among the oxides present in the slag at $1600^{\circ} \mathrm{C}$. The table further reveals that the fastest rate was obtained by $\mathrm{MnO}$ followed by $\mathrm{Fe}_{2} \mathrm{O}_{3}, \mathrm{Cr}_{2} \mathrm{O}_{3}, \mathrm{SiO}_{2}$ and $\mathrm{NiO}$ had the slowest rate. The calculated mass transfer of $\mathrm{NiO}$ from the slope was found to be $3.77 \times 10^{-6} \mathrm{~m} / \mathrm{min}$. Actual values of the mass transfer coefficients of these oxides are also presented in the table. It can be concluded that the mass transfer of $\mathrm{NiO}$ in the slag phase is rate controlling.

Table 5. Mass transfer coefficients of the oxides at $1600^{\circ} \mathrm{C}$

\begin{tabular}{c|c|c|c|c|c}
\hline Compounds & $\mathrm{Fe}_{2} \mathbf{O}_{3}$ & $\mathrm{Cr}_{2} \mathbf{O}_{3}$ & $\mathbf{N i O}$ & $\mathbf{M n O}$ & $\mathrm{SiO}_{2}$ \\
\hline $\mathbf{k}_{\mathbf{s}}(\mathbf{m} / \mathbf{m i n})$ & $1.56 \mathrm{x}$ & $1.06 \mathrm{x}$ & $3.77 \mathrm{x}$ & $5.56 \mathrm{x}$ & $5.94 \mathrm{x}$ \\
& $10^{-5}$ & $10^{-5}$ & $10^{-6}$ & $10^{-5}$ & $10^{-6}$ \\
\hline
\end{tabular}

In this investigation, the kinetics of slag-metal reactions was stimulated by metal phase control mechanism and slag phase control mechanism. Results obtained from the experiments showed that the metal phase control was the dominating mechanism in the study as seen from the degree of fit of the experimental data to such mechanism.

\section{Conclusion}

Mass transfer coefficients were obtained from smelting of mixed low-grade chromite and nickel laterite ores at $1600^{\circ} \mathrm{C}$ using metal phase and slag phase rate-controlling mechanisms in the slag-metal reactions. Experimental studies showed that the fastest rate was obtained by Mn followed by $\mathrm{Si}, \mathrm{Fe}, \mathrm{Ni}$ and $\mathrm{Cr}$. The mass transfer coefficients of $\mathrm{Mn}, \mathrm{Si}$, $\mathrm{Fe}, \mathrm{Ni}$, and Cr were $7.72 \times 10^{-5} \mathrm{~m} / \mathrm{min}, 1.24 \times 10^{-5} \mathrm{~m} / \mathrm{min}, 2.86$ x $10^{-6} \mathrm{~m} / \mathrm{min}, 2.73 \times 10^{-6} \mathrm{~m} / \mathrm{min}$ and $1.68 \times 10^{-6} \mathrm{~m} / \mathrm{min}$, respectively at $1600^{\circ} \mathrm{C}$. The mass transfer of $\mathrm{Cr}$ in the metal phase is rate controlling with a mass transfer coefficient of $1.6812 \times 10^{-7} \mathrm{~m} / \mathrm{min}$ lower in magnitude than the mass transfer coefficients of manganese, silicon, iron and nickel in the crude alloy.

Using the slag phase control mechanism, it was observed that the fastest rate was obtained by $\mathrm{MnO}$ followed by $\mathrm{Fe}_{2} \mathrm{O}_{3}$, $\mathrm{Cr}_{2} \mathrm{O}_{3}, \mathrm{SiO}_{2}$ and $\mathrm{NiO}$ had the slowest rate. The mass transfer coefficients of $\mathrm{MnO}, \mathrm{Fe}_{2} \mathrm{O}_{3}, \mathrm{Cr}_{2} \mathrm{O}_{3}, \mathrm{SiO}_{2}$ and $\mathrm{NiO}$ were 5.56 x $10^{-5} \mathrm{~m} / \mathrm{min}, 1.56 \times 10^{-5} \mathrm{~m} / \mathrm{min}, 1.06 \times 10^{-5} \mathrm{~m} / \mathrm{min}, 5.94 \times 10^{-}$ ${ }^{6} \mathrm{~m} / \mathrm{min}$ and $3.77 \times 10^{-6} \mathrm{~m} / \mathrm{min}$, respectively. It can be concluded that the mass transfer of $\mathrm{NiO}$ in the slag phase is rate controlling. The dominating mechanism of the study as seen from the degree of fit of the experimental data to such mechanism was the metal phase control.

Results obtained from the experiments also showed that the metal phase control was the dominating mechanism in the study as seen from the degree of fit of the experimental data to such mechanism. Moreover, the $k_{m}$ values of the metals are generally lower compared to the $k_{s}$ values of the slags so that mass transport in the metal is rate controlling. However, further works are required to elucidate the precise mechanisms of mass transfer of two immiscible liquids like metal and slag produced from direct smelting of mixed chromite and nickel laterite ores because of the presence of gaseous products as well as the side reactions involved.

\section{Acknowledgment}

The authors wish to acknowledge the guidance of Dr. Nathaniel M. Anacleto and the financial support of Engineering Research and Development for Technology (ERDT) and Commission on Higher Education (CHED).

This is an Open Access article distributed under the terms of the Creative Commons Attribution License

\section{References}

[1] D. Mazumdar and J. W. Evans, "Modeling of steelmaking processes", CRC Press. Engineering \& Technology, p. 85, 2009.

[2] Y. Fautrelle, F. Debray, and F. Dalard, "Mass transfer measurement at a stirred liquid-liquid interface by means of an electrochemical method", American Institute of Aeronautics and Astronautics, 353357, 1998.

[3] L. D. De Oliveira Campos, "Mass transfer coefficients across dynamic liquid steel/slag interface", Mechanics [physics]. Université de Bordeaux, 2017.

[4] R. P. Tavares, "Mass Transfer in Steelmaking Operations, Mass Transfer in Multiphase Systems and its Applications", Prof. Mohamed El-Amin (Ed.), 2011, InTech, Available from: http://www.intechopen.com/books/mass-transfer-in-multiphasesystems-and-its-applications/mass-transfer-insteelmakingoperations

[5] S. Horiuchi, Md. A. Uddin, Y. Kato, Y. Takahashi, and Y. Uchida, "Mass Transfer between Different Phases in a mechanically-stirred vessel and its comparison with that in a gas-stirred one", ISIJ International, 54(1), 87-93, 2014.

[6] M. Martin, M. Rendueles, and M. Diaz, "Steel-slag mass transfer in steel converter, bottom and top/bottom combined blowing through cold model experiments", Chemical Engineering Research and Design, 83(A9), 1076-1084, 2005.

[7] M. A. Rhamdhani, G. A. Brooks, and K. S. Coley, "Kinetics of metal/slag reactions during spontaneous emulsification", Metallurgical and Materials Transactions B, 36B, 219-227, 2005.

[8] J. Diao, X. Liu, T. Zhang, and B. Xie, "Mass transfer of phosphorus in high-phosphorus hot-metal refining", International Journal of Minerals, Metallurgy and Materials, 22(3), 249-253, 2015.

[9] H. Xie and F. Oeters, "Kinetics of mass transfer of manganese and silicon between liquid iron and slags", Steel Research, 66(12), 501508, 1995.

[10] R. D. Laranjo, and N. M. Anacleto, "Production of Fe-Cr-Ni-Mn alloy by direct smelting of mixed low-grade chromite, nickel laterite and manganese ores with low-grade coal as reductant", International 
Journal of Metallurgical \& Materials Science and Engineering (IJMMSE), 7(1), 1-12, 2017.

[11] F. D. Richardson, "Physical Chemistry of Melts in Metallurgy Vol. 2", Academic Press, London, p. 420, 1974

[12] B. Deo and R. Boom, Fundamentals of Steelmaking Metallurgy, Prentice Hall International, UK, 1993.
[13] R. D. Laranjo, and N. M. Anacleto, "Direct smelting process for stainless steel crude alloy recovery from mixed low-grade chromite, nickel laterite and manganese ores", J. Iron Steel Res. Int., 25(5), 515-523, 2018. 